$12-1-2017$

\title{
Perceived Self-to-Other Similarity as a Mediator of the Effects of Gender and Racial Composition on Identification in Small Groups
}

Randi L. Garcia

Smith College, rgarcia@smith.edu

Follow this and additional works at: https://scholarworks.smith.edu/psy_facpubs

Part of the Psychiatry and Psychology Commons

\section{Recommended Citation}

Garcia, Randi L., "Perceived Self-to-Other Similarity as a Mediator of the Effects of Gender and Racial Composition on Identification in Small Groups" (2017). Psychology: Faculty Publications, Smith College, Northampton, MA.

https://scholarworks.smith.edu/psy_facpubs/14 
Perceived Self-to-Other Similarity as a Mediator of the Effects of Gender and Racial Composition on Identification in Small Groups

Randi L. Garcia

Smith College

Author Note

Randi L. Garcia, Departments of Psychology and Statistical and Data Sciences, Smith College.

I would like to thank David A. Kenny for his advice on previous versions of this manuscript and Judith Y. Tan for her help with data collection. I would also like to thank Andrew L. Stewart for his help and support during my work on this project.

Correspondence concerning this article should be addressed to Randi L. Garcia, Department of Psychology, Smith College, Bass 415, Northampton, MA 01063. E-mail: rgarcia@smith.edu. 


\begin{abstract}
Two group studies tested the mediating role of perceived diversity in the link between actual demographic composition and an individual's identification with a small group. In these studies, a new type of dyadic perceived diversity — self-to-other perceived similarity — is introduced and measured. Further, a Group Actor Partner Interdependence Model (GAPIM) approach was used to test mediation of the link between actual demographic composition and identification by perceived self-to-other similarity. In Study 1, 4- and 5-person small groups varying in gender composition interacted face-to-face. Results showed mediation of the effect of similarity in gender on group identification by self-to-other similarity. In Study 2, race and gender were experimentally manipulated by showing pictures of other group members with whom the participants expected to interact. Study 2 found evidence for mediation of the effect of gender similarity as well as effects of racial composition on identification by perceived self-to-other similarity. Complexities due to intersecting identities and levels of analysis inherent in psychological group research are discussed and future research directions are suggested.
\end{abstract}

Keywords: small groups, group identification, group actor partner interdependence model, diversity, levels of analysis 
Perceived Self-to-Other Similarity as a Mediator of the Effects of Gender and Racial Composition on Identification in Small Groups

As the economy becomes increasingly global, and work teams are increasing in diversity, it is crucial to understand the process by which demographic differences between group members might facilitate or hinder small group identification. Self-Categorization Theory (Turner, Hogg, Oakes, Reicher, \& Wetherell, 1987) asserts that identifying with a group —i.e., seeing one's self as a member of a group - is a necessary first step to being influenced by the group. Empirically, identification has been linked to many positive outcomes including increased liking of the group (Harrison, Price, \& Bell, 1998; O'Reilly, Caldwell, \& Barnett, 1989), greater perceptions of the group as a unit, often referred to as entitativity (Campbell, 1958; Castaño, Watts, \& Tekleab, 2013; Seashore, 1954), increased cohesiveness (Lea, Spears, \& Watt, 2007), and higher productivity (Jackson et al., 1991).

Pre-existing demographic differences, such as belonging to different social groups (e.g., based on gender, race, or ethnicity), might hinder people's identification with a team of diverse individuals. Indeed, many studies have found that demographic differences are associated with lower identification (Tsui, Egan, \& O'Reilly, 1992; see Milliken \& Martins, 1996 for a review). However, it is important to note that some have found the opposite effect in groups with inductively formed identities (i.e., when group identity is formed by the recognition of group members' unique contributions; Jans, Postmes, \& Van der Zee, 2012), groups with strong distinctiveness norms (Hornsey \& Jetten, 2004; Jetten, McAuliffe, Hornsey, \& Hogg, 2006; Rink \& Ellemers, 2007), or for people higher in social identity complexity and diversity beliefs (Hohman, Dahl, \& Grubbs, 2016; van Dick, van Knippenberg, Hagele, Guillaume, \& Brodbeck, 2008). Adding complexity to this issue, a recent body of research has begun to distinguish 
between actual and perceived diversity, examining the perception of diversity as an important construct in its own right (see Shemla, Meyer, Greer, \& Jehn, 2014, for a review). The psychological process by which people identify with less diverse groups is assumed to involve the perception of this diversity (for example, see Jehn, Northcraft, \& Neale, 1999, and Pelled, 1996), but this mechanism is rarely tested in the literature (for exceptions see Amoit, Terry, \& McKimmie, 2012; Harrison, Price, Gavin, \& Florey, 2002). The current research addresses this gap by empirically testing the extent to which perceived similarity mediates the relationship between demographic composition and identification with small groups.

Harrison et al. (1998) make an important distinction between "surface-level" characteristics - features that are visible and can be perceived readily — and "deep-level" characteristics, such as personality and ability. The current research focuses on actual surfacelevel diversity (i.e., gender and race) because demographic differences are most visible as groups are in their beginning stages (Harrison et al., 2002) and because people may rely on demographic differences as a cognitive heuristic to infer deep-level differences (Burns \& Keswell, 2015). Furthermore, surface-level diversity has also found to be a barrier to achieving group consensus in deep-level characteristics, with one study finding that consensus in values was harder to achieve in more culturally diverse groups than in more homogenous groups (Meeussen, Schaafsma, \& Phalet, 2016).

Many social psychological theories would predict the relationship between perceived similarity and identification. Social Identity Theory explains how people feel positively toward others who are members of the same social groups in an effort to boost their own group's value and in turn their individual value (Tajfel \& Turner, 1979). Indeed, people often feel more positively toward their ingroup than the outgroup - a phenomenon referred to as in-group bias 
(Brewer, 1979). van Knippenberg, De Dreu, and Homan (2004) have proposed the Categorization-Elaboration Model (CEM), a comprehensive model explaining the effects of group composition on a host of outcomes including productivity and identification. In the CEM the negative route from diversity to identification with the group is mediated by categorization. Directly applying Self-Categorization Theory (Turner et al., 1987), the CEM also makes predictions that the link between diversity and categorization is moderated by normative fit (e.g., contextual factors), and accessibility of the specific diversity characteristics - important pieces of the process for future studies to consider.

Although there is an emerging field of perceived diversity (Shemla et al., 2016), no studies have directly tested the role of perceived diversity as a mediator of the actual diversity identification link. As one exception, Hentscel, Shemla, Wegge, and Kearney (2013) studied the effect of perceived team diversity on identification (as mediated by affect towards the group and moderated by diversity beliefs) in 271 people in 44 teams across 21 companies, and in their team-level analyses, they controlled for actual group demographic diversity in age, gender, educational, nationality, and tenure. As evidence of the conceptual distinction between actual and perceived diversity, they found perceived diversity to be a unique predictor of identification while actual diversity had no direct effect on identification. Other studies have examined different, but closely related, constructs. In one four-wave longitudinal study of student work groups, Harrison et al. (2002) found that perceptions of diversity mediated the effects of actual diversity on team social integration, a construct closely related to, but different from, group identification. Lastly, in a study examining the negative effects of subgroup divides after an organizational merger, Amoit et al. (2012) found that perceived diversity explained, in part, the effect of actual status differences on identification. In sum, actual demographic diversity has 
been found to lead to perceived diversity, which, in turn, has been linked to lower levels of small group identification. Unanswered questions that remain are, just how much of the relationship between composition and identification is explained by perceived similarity? And, does the level of measurement and analysis of perceived diversity matter?

In their recent review paper, Shemla and colleagues (2016) distinguish between three types of perceived diversity: 1) self-to-team perceived dissimilarity-how similar am I to the group? 2) perceived subgroup splits - to what extent are there subgroups in this group? and 3) perceived team diversity—how diverse is this team? There is one type of perceived diversity missing from this list—how similar am I to each other person in the group? I call this self-toother perceived similarity, and it represents a different level of analysis from the three types of perceived diversity - the dyadic level. Self-to-other perceived similarity is important to define and measure because dyadic relationships are the smallest unit of social relationships, and measuring the psychological dynamics of groups at this lower level will allow effects at a higher level of analysis to emerge empirically. Further, it is important to distinguish perceived similarity from other similar constructs including depersonalization/self-stereotyping_I am a typical group member (Turner et al., 1987; Voci, 2006), and self-anchoring_people in this group must be like me (Cadinu, \& Rothbart, 1996; van Veelen, Otten, \& Hansen, 2013). With lack of any additional information about group content and purposes, perhaps demographic differences are used in this self-anchoring process. That is, in low clarity (i.e., unclear) groups, if people share demographic characteristics they will perceive more self-to-other similarity which will lead to self-anchoring. The current studies test the first part of this process: the demographic differences to self-to-other perceived similarity link. 
If group identification is measured at the individual level, optimally, the effects of actual diversity and perceived diversity would also be measured at the individual level (Harrison \& Klein, 2007). By far the most common way actual diversity has been measured is with the variability in the group members' characteristics (e.g., variance in gender, Tsui et al., 1992; Tsui \& Gutek, 1999). The variance of the group members attributes is calculated for each group-i.e., it is measured at the group level — and the similarity in the demographic variable of each member to the others is lost. In a group composed of one woman and four men, the group diversity in gender is low, but the one woman is very different in gender from the rest of the group. In contrast, relational demography paradigms, like the one employed here, investigate the effect of a person's fit into the group or the person's similarity to the other members of the group (Elfenbein \& O'Reilly, 2007). The current study makes use of the Group Actor-Partner Interdependence Model (GAPIM; Garcia, Meagher, \& Kenny, 2015; Kenny \& Garcia, 2012), a new model for testing the decomposed effects of group composition, which optimally captures both person fit and diversity simultaneously. More details on this model are discussed below.

\section{Current Studies}

To test if the effects of demographic diversity on group identification are mediated by perceived self-to-other similarity, I conducted two studies. In Study 1, I examined 4- to 5- person groups interacting face-to-face that varied in gender composition. After the interaction portion of the study, perceived self-to-other similarity was measured with round-robin ratings of how similar participants felt to each of their other group members, and then participants completed a measure of small group identification. I expected that the aggregate of participants' perceived self-to-other similarity would mediate the effects of gender composition on identification with the small group. In Study 2, I manipulated both gender and racial group composition. Whereas 
Study 1 involved actual face-to-face interactions, Study 2 used a paradigm in which participants believe that they will be interacting with others, but they do not actually interact.

\section{Study 1}

Study 1 used groups interacting face-to-face to test the hypothesis that self-to-other similarity mediates the effect of gender composition on group identification. Participants in these groups, which varied in gender composition, rated how similar they felt towards each other person in their group and also responded to questions about their feelings towards their group as a whole.

\section{Method}

Participants. Fifty-eight groups of four to five students from a large public university in the Northeast of the United States participated. Gender composition varied across groups. Six groups were eliminated because one person in their group had missing gender information. Without information about the group composition variable from everyone in a group, all of the GAPIM terms for every person in the group cannot be computed. The remaining 241 participants in 52 four- or five-person groups were 87 men $(36.1 \%)$ and 154 women. Of the 19 four-person groups, four were all women, seven had one man, three had two men, five had three men; of the 33 five-person groups, nine were all women, five had one man, nine had two men, six had three men, two had four men, and two groups were all men. The average age was $18.57(M d n=18)$. The sample included 24 Asian-Americans (10.0\%), 11 Latino(a)s (4.6\%), 6 Black/AfricanAmericans (2.5\%), 195 White/European-Americans (80.9\%), and 5 people indicated another $(2.1 \%)$ race/ethnicity. 
Procedure. After signing up for one of five slots at a given time, participants arrived at the lab in groups of four to five students varying in gender composition. ${ }^{1}$ A group of four was formed if there was one no show, or if only four people signed up for that time slot. If only three people showed up or signed up, all participants completed an individual survey designed for another, unrelated, study. Note that participants were not randomly assigned to gender compositions, but compositions were passively allowed to vary. Participants were led into the interaction room and sat around a round table marked with letters- " $A$ ", "B", "C", "D", and "E" — on top of the table in front of each of the five chairs positioned around it. If there were only four participants then the "E" position was always left empty. They were told that the researchers were investigating group composition and interactions, and consent was obtained. They then filled out a short demographic questionnaire stating their gender, and to collect information about other potentially relevant characteristics such as race, sexual orientation, and religiosity. ${ }^{2}$ Due to the lack of racial diversity of the sample $(80.9 \%$ White), Study 1 does not consider racial group composition, only gender composition.

For the group interaction portion of the study, the participants first had 5 minutes to write an individual short story about a picture, and then these stories were discussed as a group for approximately 5 minutes. In these group discussions, they were instructed to consider strengths and weaknesses of each person's story in turn. To facilitate this discussion, they were given a short list of potential strengths and weaknesses. Lastly, the group was asked to create one group story about the same picture. They were not given a specific amount of time for the group story, but usually the story was completed within 5 to 10 minutes. Unfortunately, the amount of time

\footnotetext{
${ }^{1}$ Due to an oversight, participants were not screened for prior acquaintance; however, students were mostly new to campus (first or second semester freshman) and the participants pool was large $\mathrm{N} \approx 1,400$.

${ }^{2}$ Sexual orientation and religiosity could have potentially been used as deep-level diversity characteristics; however, focusing on surface-level diversity, we only used gender in the current study.
} 
spent on group stories was not recorded. The picture was a cartoon of two aliens standing on an unfamiliar planet. Leadership was not assigned, and there was no requirement about whose individual ideas were to be incorporated into the final story. The experimenter - who alternated between two research assistants, one male and one female-was not present in the room while the individual stories were being written, nor during the group discussion or the writing of the group stories. Groups were monitored on screens in a connecting room. After they finished their group stories, the stories were collected, and members were asked to complete a series of postinteraction questionnaires while sitting behind partitions for privacy.

Measures. Self-to-other perceived similarity. Round-robin ratings of perceived similarity to each other group member were assessed first. Participants used the letters marked on the top of the table to identify their group members. Specifically, participants were asked, "How similar did you feel to this person?" for each group member and responded on a $0-$ Not at all to $5-A$ great deal scale. Thus, the similarity scale only assesses general self-to-other perceived similarity, not perceived dissimilarity, which could have been measured independently (Shemla et al., 2016). To test for mediation, similarity ratings were aggregated up to the individual level—e.g., in a 4-person group, the mean of person A's ratings of members B, C, and D was calculated.

Small group identification. To capture participants' identification with the group, a 4component [i.e., satisfaction, solidarity, in-group self-stereotyping (ISS), and in-group homogeneity (IGH)] measure was given (Jans, Leach, Garcia, \& Postmes, 2015). The satisfaction and solidarity components measure group self-investment — of primary interest in the current studies_-while the ISS and IGH components measure self-definition. Example items include "I am glad to be in this group," "I feel a bond with this group," "People in this group 
have a lot in common with each other," and "I have a lot in common with the average person in this group," for satisfaction, solidarity, IGH, and ISS, respectively. In the current studies, only the two self-investment subscales, satisfaction and solidarity, were used as identification measures because the two self-definition subscales, ISS and IGH, were thought to be too conceptually close to perceived self-to-team diversity and perceived group diversity, respectively (Shemla et al., 2016). ${ }^{3}$ The four items that measure satisfaction with being in the small group formed a reliable scale $(\alpha=.899, M=4.61, S D=1.23)$, as did the three solidarity items ( $\alpha=$ $.783, M=3.55, S D=1.27)$. The averages of the items for each scale were then used as participants' scores for each component of small group identification. The correlation between the two subscales was moderate, $r=0.73, p<.001$.

\section{Results and Discussion}

Analysis strategy. Figure 1 shows the mediation model used for the analysis. Imagine there is a group with one woman, named Alyssa, and three men. For individual outcomes, such as participants' identification with the small group, the GAPIM decomposes actual group diversity into four effects: 1) actor gender-Alyssa is a woman, 2) the gender of the others (called others gender - all three of the others are men), 3) the actual similarity in gender of the actor to the rest of the group (actor similarity-Alyssa is different from everyone), and 4) the actual similarity in gender of the rest of the group members to each other (others similarity-the men are all similar to each other in gender). In Figure 1, the $c$ paths are the total effects of group composition on group identification - there are eight $c$ paths. Paths $a$ are the effects of group composition on aggregated perceived self-to-other similarity — there are four $a$ paths. Paths $b$ are

\footnotetext{
${ }^{3}$ The three IGH items $(\alpha=.887)$ and the three ISS items $(\alpha=.898)$ formed reliable scales. In both Study 1 and Study 2 the same statistical models were estimated using these two self-definition subscales as measures of identification and a similar pattern of results was found. Detailed results from these models are available upon request.
} 
the direct effects of perceived self-to-other similarity on group identification controlling for group composition - there are two $b$ paths. The product of $a$ and $b$, or $a b$, represents the eight indirect effects of group composition on identification through perceived self-to-other similarity, and the significance tests of these eight quantities provide evidence for the presence of mediation. ${ }^{4}$ Lastly, $c^{\prime}$ is the direct effect of group composition on group identification controlling for perceived self-to-other similarity; there are also eight of these paths.

The outcome, identification (i.e., satisfaction and solidarity), was measured at the individual level and the mediator, self-to-other perceived similarity, was measured at the dyadic level. First, the GAPIM for individual outcomes (Garcia, Magher, \& Kenny, 2015; Kenny \& Garcia, 2012) was used to test the effects of gender composition on identification - the $c$ and $c$, paths in Figure 1. Second, although perceived similarity was measured at the dyadic level, these three to four ratings given by each participant were aggregated to the individual level and then used as a predictor of the group identification components, controlling for the GAPIM terms (the $b$ paths in Figure 1). To test the effects of gender composition on perceived self-to-other similarity, I used the aggregated self-to-other similarity ratings as the outcome to test the effects of gender composition on perceived similarity ( $a$ paths in Figure 1). Multilevel Modeling with restricted maximum likelihood estimation (REML) was used for all analyses to account for the nonindependence in group members' aggregated perceived self-to-other similarity ratings and group identification scores. The indirect effects were tested using the Monte Carlo Method for

\footnotetext{
${ }^{4}$ In these analyses the presence of significant indirect effects can only be taken as evidence for mediation but not the strict confirmation of mediation. As Judd and Kenny (2010) explain, this is because there is the possibility for biased (inflated) indirect effects given that the mediator and the outcome variables may share common unmeasured causes. Thus, care needs to be taken in drawing conclusions about mediation of the composition effects on identification by perceived similarity, and only take the results as evidence for the possibility of mediation.
} 
Assessing Mediation (MCMAM; Selig \& Preacher, 2008). The results from these analyses are contained in Table 1.

Total and direct effects. There was a statistically significant total effect of actor similarity on satisfaction with the group, $b=0.30, S E=0.15, p=.044$ - the more similar in gender the actor was to the others, the more satisfied the actor was. There was significant group variance in satisfaction, $\sigma_{\text {group }}^{2}=0.18, S E=0.09, p=.024$, that is, some groups were more satisfied than other groups. The intraclass correlation $(I C C)$, however, was small $(I C C=.126)$.

Consistent with the results for satisfaction, there was a significant total effect of actor similarity in gender on small group solidarity in the positive direction, $b=0.31, S E=0.15, p=$ .037 , and there was a negative statistically significant total effect of others similarity on solidarity, $b=-0.37, S E=0.16, p=.025$. People reported the most solidarity when they were more similar in gender to their group members but the others were more diverse in gender. For solidarity there was also group variance $\sigma_{\text {group }}^{2}=0.162, S E=0.09, p=.040$, and the ICC was small, .106.

In sum, there is evidence that the more similar the actor is to the others and the more diverse that the others are, the more identified the participant was with the group. This pattern was consistent across the two components of identification, satisfaction and solidarity. Note that the effect of actor similarity and others similarity are opposite signs but of equal magnitude; this pattern indicates that if we had instead measured diversity at the group level (a weighted average of these two GAPIM terms), we would have found no effects of gender composition. These seemly contradictory findings may point to process where distinctiveness and belonging motives are in balance (Ormiston, 2016). 
The effects of gender composition on the actor's aggregated perceived self-to-other similarity were also tested. This is the $a$ path in Figure 1, and the results are presented in the first column of Table 1 . There was only a significant effect of actor gender similarity on perceived self-to-other similarity, $b=0.22, S E=0.11, p=.049$.

Next, the $b$ and $c$ ' paths were tested, and the indirect effects of group composition on group identification through self-to-other perceived similarity are assessed. In addition to perceived similarity as a predictor, the four GAPIM terms were included in the model. Consistent with expectations, average self-to-other perceived similarity significantly predicted satisfaction, $b=0.66, S E=0.07, p<.001$, and solidarity, $b=0.62, S E=0.08, p<.001$. Each of these similarity effects is estimated controlling for the group composition effects of gender. Thus, the more the actor perceived him or herself to be similar to the other group members, the more he or she identified with the group. Further, when controlling for perceived similarity, there were no longer significant direct effects of actual actor similarity in gender on the two identification components of identification ( $c$ 'paths) — evidence that the effect of gender similarity on identification is mediated by perceived self-to-other similarity.

Indirect effects. Figure 2 depicts the reduced mediation model where only the effects of actual actor similarity in gender on the group identification components through perceived similarity are considered. I tested these two indirect effects using the MCMAM (Selig \& Preacher, 2008). The indirect effect of actual actor similarity in gender on satisfaction through perceived similarity was significant, $a b=0.15,95 \% C I=[0.002,0.304]$, as was the indirect effect on solidarity, $a b=0.14,95 \% C I=[0.001,0.287]$. Perceived self-to-other similarity mediated $44.03 \%$ of the actual actor gender similarity effect on solidarity and $50.00 \%$ of the effect on satisfaction. 
In summary, as in previous research, the current study found a positive link between group homogeneity (specifically actual actor similarity in gender) and identification. The tests of indirect effects indicate that there is evidence that perceived self-to-other similarity mediates this link between composition and identification. In addition, the direct effects of actor similarity on the two components of group identification were no longer significant when controlling for perceived similarity. However, the effect size of the indirect effect was only $44.03 \%$ mediated for solidarity and $50.00 \%$ mediated for satisfaction, leaving room for a conceptual and theoretical distinction between actual and perceived diversity.

These findings lend support for the proposed categorization link in the CEM (van Knippenberg et al., 2004), and they provide evidence for the assumption that the effects of actual gender differences on identification is due, in part, to group members perceiving differences between themselves and the other group members. Study 2 sought to replicate Study 1 by again looking at gender composition and also to expand on Study 1 by also investigating the effects of racial composition.

\section{Study 2}

In an experimental laboratory study, Study 2 investigated the effects of multiple demographic characteristics on perceptions of similarity and, in turn, group identification. The gender and racial composition of a group with whom participants thought that they would interact was manipulated. Controlling the demographic composition of the "group" made it possible to create the complete range of racial and gender compositions. Study 2 makes an important extension by exploring actual racial composition in addition to actual gender composition, and by experimentally manipulating composition. It was expected that the effects 
of group composition — namely actor similarity in both gender and race—on small group identification would be mediated by perceived self-to-other similarity.

\section{Method}

Participants. A total of 156 people participated in this study; however, to simplify the methodology and analyses only those who self-identified as either White or Black $(\mathrm{N}=116)$ were included in the analyses. Further, 6 participants had missing data on the crucial small group identification measure and these participants were excluded from the analyses - they were assumed to be missing completely at random (MCAR). The final analysis sample consisted of 110 participants, 19 Black (17.3\%) and 91 White. There were 48 men (43.6\%) and 62 women whose ages ranged from 18 to 42 with the average age being 19.45.

Procedure. Participants arrived at the laboratory, and the experimenter then brought them into a cubicle and had them read and sign the consent form. The experimenter then welcomed the participant to the "Diverse Discussions" study and told them that "we are interested in how groups with members who have many different characteristics, including different races and genders, interact and how they feel about these interactions." To maintain the cover study, the experimenter told the participants that we already have the other group members' photos and asked if they brought a digital photo. If they did not, the experimenter took the participant's picture. The "Diverse Discussions" cover story was taken from Goff, Steele and Davies (2008) who found that participants did not believe they would be interacting with two Black participants randomly because this situation was highly improbable given the racial makeup of their university. The institution where the current study was conducted has a similar issue with a racial make-up being skewed heavily towards White students. During the debriefing 
session participants were asked if they believed that they were to interact with the group they saw in the pictures, and the vast majority of participants were not suspicious.

While the experimenter uploaded the participant's picture into the online survey, the participant was given the group's discussion topic and was asked to read through background information and discussion points on the computer about this topic. After the participant was done reading the information, he or she was shown their discussion partners' pictures on the computer. They also saw their own picture on the screen along with four other pictures. Pictures of four White women, four White men, four Black women, and four Black men were selected from public internet sites. The racial and gender composition of the pictures the participants saw were systematically manipulated across all possible compositions. ${ }^{5}$

The participants were instructed to answer questions about each group member. They answered these questions while all the group pictures remained on the screen. Each picture was labeled with a letter (e.g., "Person A") and the font of this label changed to bold-underline while the participant answered questions about that person. As in Study 1, among these questions ${ }^{6}$ was one asking how similar they felt to each of the other group members (6-point scale from 0 to 5). Next, there were questions that the participant answered about the group in general. The same 4component measure of group identification that was given in Study 1 was used (Jans et al., 2015). The four items that measure satisfaction with being in the small group formed a reliable

\footnotetext{
${ }^{5}$ There are 25 different types of groups: five different gender composition types [zero to four men (or women)] crossed with five different racial composition types [zero to four White (or Black)]. For nine of these composition types there are multiple ways to comprise the group. For example, in the 2 men -2 White people combination, this group type could be formed in three different ways: 1) one White woman, one White man, one Black woman and one Black man, 2) two White men and two Black women, and 3) two Black men and two White women. One group was used from each of the 25 types except for the two men - two White people situation where two groups were used (i.e., the first two listed above). Thus, there were 26 levels of group composition that the participant could be assigned to. For each of these 26 levels, pictures of the White men, Black men, White women, and Black women were randomly assigned.

${ }^{6}$ Other questions included trait ratings to examine a separate research question unrelated to the current study.
} 
scale $(\alpha=.85, M=4.48, S D=1.05)$ as did the three solidarity items $(\alpha=.86, M=3.48, S D=$ 1.25). ${ }^{7}$ The two subscales were correlated as in Study $1, r=0.69, p<.001$. After completing the measures, they were informed that the study was actually over, and there would not be a group interaction. They were then fully debriefed and thanked for their participation.

\section{Results}

As in Study 1, the current study tested if perceived self-to-other similarity mediated the effects of actual gender and racial composition on small group identification. The mediation occurs at the level of the participant, and thus, participants' judgments of perceived similarity were again aggregated. The four GAPIM terms for gender (i.e., actor gender, others gender, actor similarity in gender, and others similarity in gender) and four terms for race (i.e., actor race, others race, actor similarity in race, and others similarity in race) were used as predictors of the two identification components. The final mediation model contains eight actual demographic composition terms as the predictor variables (i.e., four for gender and four for race), one perceived similarity term as the mediator variable and the two components of small group identification as outcome variables (i.e., satisfaction, solidarity). Path Analysis with maximum likelihood estimation was used to estimate all structural paths and bootstrapped confidence intervals were used to test the indirect effects. Disturbance covariances between the two identification components ${ }^{8}$ were included, and thus, this was a saturated model.

As in Study 1, there was a significant effect of actual actor similarity in gender on aggregated perceived self-to-other similarity ( $a$ path), $b=0.25, S E=0.12, p=.037$, such that the more similar in gender, the more similar the participant felt to the others. There were no other

\footnotetext{
7 The three IGH items $(\alpha=.82)$ and the three ISS items $(\alpha=.90)$ also formed reliable scales.

${ }^{8}$ A model including all four identity components as outcome variables produced a similar pattern of result. Estimates from this model are available upon request.
} 
significant effects of gender. There was also a statistically significant effect of actor race on perceived similarity, $b=0.36, S E=0.11, p<.001$, such that White participants felt more similar to their group members than Black participants. Contrary to expectations, there was no statistically significant effect of actual actor similarity in race on perceived similarity, $b=-0.13$, $S E=0.15, p=.389$, as there was for gender. There was however, a statistically significant effect of others similarity in race on perceived similarity, $b=-0.31, S E=0.14, p=.028$, such that the more different the others were to each other the more similar the actor felt on average to these group members, perhaps evidence of optimal distinctiveness (Brewer, 1991) processes for race. This pattern of results will be addressed fully in the discussion section.

Next, the effects of aggregated perceived self-to-other similarity on satisfaction and solidarity with the group, the $b$ paths, were tested. The effects of self-to-other similarity on the two group identification components were both statistically significant: $b=0.60, S E=0.11, p<$ .001 for satisfaction, and $b=0.70, S E=0.13, p<.001$ for solidarity.

Table 2 contains the indirect effects and their bootstrapped significance levels. As can be seen in Table 2, replicating Study 1, the indirect effect of actual actor similarity in gender on satisfaction with the group through perceived self-to-other similarity was statistically significant, $a b=0.15,95 \% C I=[0.01,0.38], 46.71 \%$ mediated, as was the indirect effect of actor similarity in gender on solidarity through perceived self-to-other similarity, $a b=0.18,95 \% C I=[0.01$, 0.34], $61.62 \%$ mediated. There was a statistically significant indirect effect of actor race on small group identification through perceived self-to-other similarity: satisfaction, $a b=0.21,95 \% C I=$ $[0.07,0.50]$, and solidarity, $a b=0.25,95 \% C I=[0.08,0.42]-$ White participants perceived more similarity between themselves and the other group members than Black participants, which 
in turn was related to higher identification. ${ }^{9}$ There were also statistically significant indirect effects of others' similarity in race on small group identification through perceived self-to-other similarity: satisfaction, $a b=-0.18,95 \% C I=[-0.45,-0.03], 79.13 \%$ mediated, and solidarity, $a b$ $=-0.21,95 \% C I=[-0.51,-0.04]$ - the more different the others were to each other in race, the more identified the participant was with the group, and this was largely due to increases in perceptions of self-to-other similarity. ${ }^{10}$ There is evidence that the negative effect of others' similarity in race and the effect of actor race are mediated fully by perceived self-to-other similarity. No other indirect effects were statistically significant but their estimates can all be found in Table 2.

Discussion. In summary, the mediation results for racial composition are less clear than they are for gender composition. As in Study 1, in Study 2, there were positive indirect effects of actual actor similarity in gender on group identification through perceived self-to-other similarity. There were also positive indirect effects of actor race on both identification components indicating that White participants identified more with the groups than Black participants and this effect was mediated through perceived self-to-other similarity. Contrary to expectations, there were no positive indirect effects of actual actor similarity in race on group identification, but there were significant negative indirect effects of others similarity in race.

\section{General Discussion}

The mediating role of perceived similarity on the link between actual group demographic composition and identification was tested in two studies. These findings provide evidence for the assumption that the link between actual group composition and group identification can be

\footnotetext{
${ }^{9}$ The indirect effect is positive, as expected, but the total and direct effects were non-significant negative effects. This is evidence of inconsistent mediation and the percent mediated cannot be computed (MacKinnon, Krull, \& Lockwood, 2000).

${ }^{10}$ For solidarity there was inconsistent mediation.
} 
explained by experiences of psychological similarity. The mediating role of perceived self-toother similarity — the extent to which a person feels similar to each other person in the group —is theorized in the van Knippenberg and colleagues (2004) Categorization-Elaboration Model (CEM); however, to my knowledge, no previous study has systematically tested the presumed mediating role of perceived diversity in this way.

Studies 1 and 2 both found evidence that perceived self-to-other similarity mediates the effects of actual gender similarity of the person to the others on small group identification. Specifically, it was found in Study 1 that actually being more similar in gender to the other group members was associated with higher identification while the similarity of the others (besides the person) decreased identification. This pattern of results may point to an optimal distinctiveness process (Brewer, 1991).

The main finding of Study 1, replicated in Study 2, was the indirect effect of actual actor similarity in gender on group identification through perceived self-to-other similarity. Further, I estimated that perceived similarity mediated only up to $50 \%$ of this effect - thus, while Studies 1 and 2 provided evidence that the effect of actual actor similarity in gender on identification may be mediated partially by perceived self-to-other similarity, there is room to theorize about other possible mechanisms that explain the effects of gender diversity. In contrast, perceived similarity did not mediate the actual similarity of the others in gender effect - thus, there was evidence that how similar the focal person was in gender to the others affected his or her self-to-other similarity, but just being in a more or less gender diverse group did not. This pattern of results points to a "person-fit" process of perceived self-to-other similarity as a mediator (Elfenbein \& O'Reilly, 2007). 
The mediation results for racial composition from Study 2 are less clear. There were positive indirect effects of actor race on both identification components indicating that White participants identified more with the groups than Black participants and this effect was mediated through similarity perceptions. Although we had no explicit status manipulation, this result is in accordance with Amoit et al. (2012) who found that higher status organization members perceived more similarity after a merger of two companies. Alternatively, this result could be due to participants' concerns with appearing prejudiced after the study was revealed to be about "Diverse Discussions." Perceived similarity did mediate the negative effect of actual other similarity in race on identification-i.e., the more similar the others, the less perceived self-toother similarity which in turn was related to lower identification. This result is contrary to what might be expected, but this negative effect could, again, be evidence of an optimal distinctiveness process. Indeed, Ormiston (2016) theorizes that individual differences in the correspondence between group composition and perceived similarity might arise based on differences in the need to belong and the need for distinctiveness.

\section{Limitations and Future Directions}

Unexpectedly, there were differences in the pattern of results depending on the specific type of demographic diversity (e.g., gender versus race) being examined. While for gender the effects of actor similarity were mediated by perceived self-to-other similarity, it was the effect of others similarity in race that was mediated by perceived similarity. More theoretical and empirical work needs to be done to think about the ways in which these two processes may be different. Perhaps diversity processes for non-arbitrary set group differences, like gender (Sidanius \& Pratto, 2001), are more likely to arise from person-fit processes while demographic differences in arbitrary set group standings produce different patterns. Further, there might be a 
more complex interplay between these two (or more) intersecting surface-level characteristics. For example, Lau and Murnighan (1998) in their work on demographic faultlines argue that subgroupings can arise within groups when demographics "line up"-e.g., all women in a group are Black while all the men are White. Parallel to the findings from the current studies, Amoit et al.'s (2012) study found that perceived subgroup divides can mediate the negative effects of the status of subgroupings on identification. Further, there is a potentially complex interplay between diversity due to race/ethnicity, gender, sexual orientation, socioeconomic status, etc., that might be best captured by interaction effects among GAPIM terms. The limitations of the sample sizes and relative lack of racial diversity in the current samples precluded tests of these interactions; however, this is a topic that deserves much more attention in future research using many more groups.

One complication with the mediation analyses we need to considered is the level of measurement of the variables involved. Because identification was measured at the individual level while perceived self-to-other similarity and group composition were measured at the dyadic level, aggregation was needed before conducting the mediation analyses. The mismatch in level of measurement highlights an unresolved issue with the conceptual, methodological, and empirical levels in small group theories and research (Harrison \& Klien, 2007; Shemla et al., 2016). Perceived similarity could have instead been operationalized by asking individuals how similar they feel to the group, or how diverse they perceive the whole group to be (Shemla et al., 2016). Whether aggregated perceived self-to-others similarity is importantly different from perceptions of similarity to the whole group is contestable, but by measuring at this lower level, we gained a more detailed description of how composition affects perceived similarity in groups. 
Relatedly, there were two other components of identification that I did not explore as outcome variables: in-group self-stereotypes (ISS) and in-group homogeneity (IGH; Leach et al, 2008). ISS is most conceptually close to self-to-team perceived similarity, while IGH is perceived whole group diversity. As these two components are a well-established piece of group identification (Leach et al., 2008; Jans et al., 2015), and perceived diversity is measured in a similar manner, more theoretical works needs to be done to tease these two conceptually close constructs apart. When do people self-define versus perceive themselves to be similar to the group? When is it possible to view the group as heterogeneous, yet still identify with the group? In heterogeneous groups, it is unclear if perceptions of similarity, however they are generated, would lead to group identification. Jans et al. (2012) showed that inductive routes to identity formation lead to identification in heterogeneous groups, but it remains a question whether or not these groups perceive similarity/dissimilarity through their shared differences, or if identification is achieved through some other psychological process.

\section{Practice Implications}

The findings from these studies have important implications for practitioners of small groups. Perceived similarities and differences were found here to transmit the effects of actual group heterogeneity, offerings a potential point of intervention for small groups. Thus, highlighting commonalities among group members might then be an important site for intervention in small groups, as it has been for reducing intergroup conflict (Dovidio, Gaertner, \& Validzic, 1998). At least when the group's identity is formed deductively and the groups are unclear-like in many newly formed work teams and potentially in group therapy sessionswhen a group member is numerically a minority, they might immediately perceive themselves to be different from the others. If inclusion is the goal, and for this person to form a healthy identity 
with the group, managers and facilitators may want to emphasize deep-level commonalities. One suggestion may be to allow for one-on-one interactions between pairs of group members which might increase feelings of self-to-other similarity which might in turn boost feelings of group identity.

\section{Conclusion}

In this set of two studies I used a novel, GAPIM, approach to test if the effects of gender and racial composition on group similarity are mediated by perceived self-to-other similarity. There was indeed evidence that the positive effect of being the same gender as one's groupmates on identification with the group is at least partially mediated by perceived similarity to these group members. The results for racial composition were more complex pointing to the possibility that we need more nuanced theorizing that depends on the specific type of demographic we are examining. Due to the evidence that this study provides that there is at least partial mediation of the effects of actual diversity on identification by perceived similarity, managers of small groups might focus group discussions on making similarity connections among members. Future directions for research include teasing apart specific types of perceived diversity from selfdefinition components of group identification and clarifying theoretical and methodological levels of analysis. 


\section{References}

Amiot, C. E., Terry, D. J., \& McKimmie, B. M. (2012). Social identity change during an intergroup merger: The role of status, similarity, and identity threat. Basic and Applied Social Psychology, 34(5), 443-455.

Brewer, M. B. (1979). In-group bias in the minimal intergroup situation: A cognitivemotivational analysis. Psychological bulletin, 86(2), 307.

Burns, J., \& Keswell, M. (2015). Diversity and the provision of public goods: Experimental evidence from South Africa. Journal of Economic Behavior \& Organization, 118, 110122.

Cadinu, M. R., \& Rothbart, M. (1996). Self-anchoring and differentiation processes in the minimal group setting. Journal of personality and social psychology, 70(4), 661.

Campbell, D. T. (1958). Common fate, similarity, and other indices of the status of aggregates of persons as social entities. Systems research and behavioral science, 3(1), 14-25.

Castaño, N., Watts, T., \& Tekleab, A. G. (2013). A reexamination of the cohesion-performance relationship meta-analyses: A comprehensive approach. Group Dynamics: Theory, Research, and Practice, 17(4), 207.

Cunningham, G. B. (2007). Perceptions as reality: The influence of actual and perceived demographic dissimilarity. Journal of Business and Psychology, 22(1), 79-89.

Dovidio, J. F., Gaertner, S. L., \& Validzic, A. (1998). Intergroup bias: status, differentiation, and a common in-group identity. Journal of personality and social psychology, 75(1), 109.

Elfenbein, H. A., \& O'Reilly III, C. A. (2007). Fitting in: The effects of relational demography and person-culture fit on group process and performance. Group \& Organization Management, 32(1), 109-142. 
Garcia, R. L., Meagher, B. R., \& Kenny, D. A. (2015). Analyzing the effects of group members' characteristics: A guide to the group actor-partner interdependence model. Group Processes \& Intergroup Relations, 18(3), 315-328.

Goff, P. A., Steele, C. M., \& Davies, P. G. (2008). The space between us: stereotype threat and distance in interracial contexts. Journal of personality and social psychology, 94(1), 91.

Harrison, D. A., \& Klein, K. J. (2007). What's the difference? Diversity constructs as separation, variety, or disparity in organizations. Academy of management review, 32(4), 1199-1228.

Harrison, D. A., Price, K. H., \& Bell, M. P. (1998). Beyond relational demography: Time and the effects of surface-and deep-level diversity on work group cohesion. Academy of management journal, 41(1), 96-107.

Harrison, D. A., Price, K. H., Gavin, J. H., \& Florey, A. T. (2002). Time, teams, and task performance: Changing effects of surface-and deep-level diversity on group functioning. Academy of management journal, 45(5), 1029-1045.

Hentschel, T., Shemla, M., Wegge, J., \& Kearney, E. (2013). Perceived diversity and team functioning: The role of diversity beliefs and affect. Small Group Research, 44(1), 33-61.

Hohman, Z. P., Dahl, E., \& Grubbs, S. (2016). Entitativity and social identity complexity: The relationship between group characteristics and personal characteristics on group identification. Self and Identity, 15(6), 638-649.

Hornsey, M. J., \& Jetten, J. (2004). The individual within the group: Balancing the need to belong with the need to be different. Personality and Social Psychology Review, 8(3), 248-264.

Jackson, S. E., Brett, J. F., Sessa, V. I., Cooper, D. M., Julin, J. A., \& Peyronnin, K. (1991). Some differences make a difference: Individual dissimilarity and group heterogeneity as 
correlates of recruitment, promotions, and turnover. Journal of applied psychology, 76(5), 675.

Jans, L., Leach, C. W., Garcia, R. L., \& Postmes, T. (2015). The development of group influence on in-group identification: A multilevel approach. Group Processes \& Intergroup Relations, 18(2), 190-209.

Jans, L., Postmes, T., \& Van der Zee, K. I. (2012). Sharing differences: The inductive route to social identity formation. Journal of Experimental Social Psychology, 48(5), 1145-1149.

Jehn, K. A., Northcraft, G. B., \& Neale, M. A. (1999). Why differences make a difference: A field study of diversity, conflict and performance in workgroups. Administrative science quarterly, 44(4), 741-763.

Hornsey, M. J., Jetten, J., McAuliffe, B. J., \& Hogg, M. A. (2006). The impact of individualist and collectivist group norms on evaluations of dissenting group members. Journal of Experimental Social Psychology, 42(1), 57-68.

Kenny, D. A., \& Garcia, R. L. (2012). Using the actor-partner interdependence model to study the effects of group composition. Small Group Research, 43(4), 468-496.

Lau, D. C., \& Murnighan, J. K. (1998). Demographic diversity and faultlines: The compositional dynamics of organizational groups. Academy of Management Review, 23(2), 325-340.

Lea, M., Spears, R., \& Watt, S. E. (2007). Visibility and anonymity effects on attraction and group cohesiveness. European Journal of Social Psychology, 37(4), 761-773.

Leach, C. W., Van Zomeren, M., Zebel, S., Vliek, M. L., Pennekamp, S. F., Doosje, B., ... \& Spears, R. (2008). Group-level self-definition and self-investment: a hierarchical (multicomponent) model of in-group identification. Journal of personality and social psychology, 95(1), 144. 
Meeussen, L., Schaafsma, J., \& Phalet, K. (2014). When values (do not) converge: Cultural diversity and value convergence in work groups. European Journal of Social Psychology, 44(6), 521-528.

Milliken, F. J., \& Martins, L. L. (1996). Searching for common threads: Understanding the multiple effects of diversity in organizational groups. Academy of management review, 21(2), 402-433.

O'Reilly III, C. A., Caldwell, D. F., \& Barnett, W. P. (1989). Work group demography, social integration, and turnover. Administrative science quarterly, 21-37.

Ormiston, M. E. (2016). Explaining the link between objective and perceived differences in groups: The role of the belonging and distinctiveness motives. Journal of applied psychology, 101(2), 222.

Pelled, L. H. (1996). Demographic diversity, conflict, and work group outcomes: An intervening process theory. Organization science, 7(6), 615-631.

Rink, F., \& Ellemers, N. (2007). Diversity as a basis for shared organizational identity: The norm congruity principle. British Journal of Management, 18(s1).

Seashore, S. E. (1954). Group cohesiveness in the industrial work group. Ann Arbor: University of Michigan.

Selig, J. P., \& Preacher, K. J. (2008). Monte Carlo method for assessing mediation: An interactive tool for creating confidence intervals for indirect effects [Computer software].

Shemla, M., Meyer, B., Greer, L., \& Jehn, K. A. (2016). A review of perceived diversity in teams: Does how members perceive their team's composition affect team processes and outcomes?. Journal of Organizational Behavior, 37(S1). 
Sidanius, J., \& Pratto, F. (2001). Social dominance: An intergroup theory of social hierarchy and oppression. Cambridge University Press.

Tajfel, H., \& Turner, J. C. (1979). An integrative theory of intergroup conflict. The social psychology of intergroup relations, 33(47), 74.

Tsui, A. S., \& Gutek, B. A. (1999). Demographic differences in organizations: Current research and future directions. Lexington Books.

Tsui, A. S., Egan, T. D., \& O'Reilly III, C. A. (1992). Being different: Relational demography and organizational attachment. Administrative science quarterly, 549-579.

Turner, J. C., Hogg, M. A., Oakes, P. J., Reicher, S. D., \& Wetherell, M. S. (1987). Rediscovering the social group: A self-categorization theory. Basil Blackwell.

Van Dick, R., Van Knippenberg, D., Hägele, S., Guillaume, Y. R., \& Brodbeck, F. C. (2008). Group diversity and group identification: The moderating role of diversity beliefs. Human Relations, 61(10), 1463-1492.

Van Knippenberg, D., De Dreu, C. K., \& Homan, A. C. (2004). Work group diversity and group performance: an integrative model and research agenda. Journal of applied psychology, 89(6), 1008.

Veelen, R., Otten, S., \& Hansen, N. (2013). Social identification when an in-group identity is unclear: The role of self-anchoring and self-stereotyping. British Journal of Social Psychology, 52(3), 543-562.

Voci, A. (2006). The link between identification and in-group favouritism: Effects of threat to social identity and trust-related emotions. British Journal of Social Psychology, 45(2), 265-284. 
Wirtz, C., \& Doosje, B. (2013). Reactions to threatening critical messages from minority group members with shared or distinct group identities. European Journal of Social Psychology, 43(1), 50-61. 
Table 1

Mediation Model Estimates for Study 1

\section{Outcome Variable}

Perceived

Self-to-Other

\begin{tabular}{lccc} 
Predictor & Similarity & Satisfaction & \multicolumn{1}{c}{ Solidarity } \\
\hline Perceived Self-to-Other Similarity & --- & $0.66^{* * * \mathrm{~b}}$ & $0.62 * * * \mathrm{~b}$ \\
Actor Gender & $-0.09^{\mathrm{a}}$ & $-0.04(0.02)$ & $-0.002(0.06)$ \\
Others Gender & $0.17^{\mathrm{a}}$ & $0.31(0.20)$ & $0.23(0.12)$ \\
Actor Similarity in Gender & $0.22^{* \mathrm{a}}$ & $0.30^{*}(0.15)$ & $0.31 *(0.18)$ \\
Others Similarity in Gender & $-0.08^{\mathrm{a}}$ & $-0.29(-0.23)$ & $-0.37^{*}(-0.32 *)$
\end{tabular}

Note. ${ }^{*} p<.05,{ }^{*} p<<.01, * * * p<.001$. ${ }^{\text {a }}$ The effects of gender composition on perceived similarity, the $a$ paths. ${ }^{\mathrm{b}}$ The effects of perceived similarity on small group identification, the $b$ paths. Inside of the shaded boxes are the total effects with the direct effects in parentheses. 
Table 2

Indirect Effects of Group Composition on Group Identification through Perceived Self-to-Other Similarity for Study 2

$\underline{\text { Identification Component }}$

Solidarity Satisfaction

\begin{tabular}{lll}
\hline Actor's Race & $0.25^{* *}$ & $0.21^{* *}$ \\
Others Race & -0.01 & -0.01 \\
Actor's Similarity in Race & -0.09 & -0.08 \\
Others Similarity in Race & $-0.21^{*}$ & $-0.18^{*}$ \\
Actor's Gender & -0.02 & -0.02 \\
Others Gender & -0.04 & -0.03 \\
Actor's Similarity in Gender & $0.18^{*}$ & $0.15^{*}$ \\
Others Similarity in Gender & -0.10 & -0.09 \\
\hline
\end{tabular}

Note. $* p<.05, * * p<.01$. Women were coded as -1 and men were coded as 1 . Black participants or partners were coded as -1 and White participants or partners were coded as 1 . 


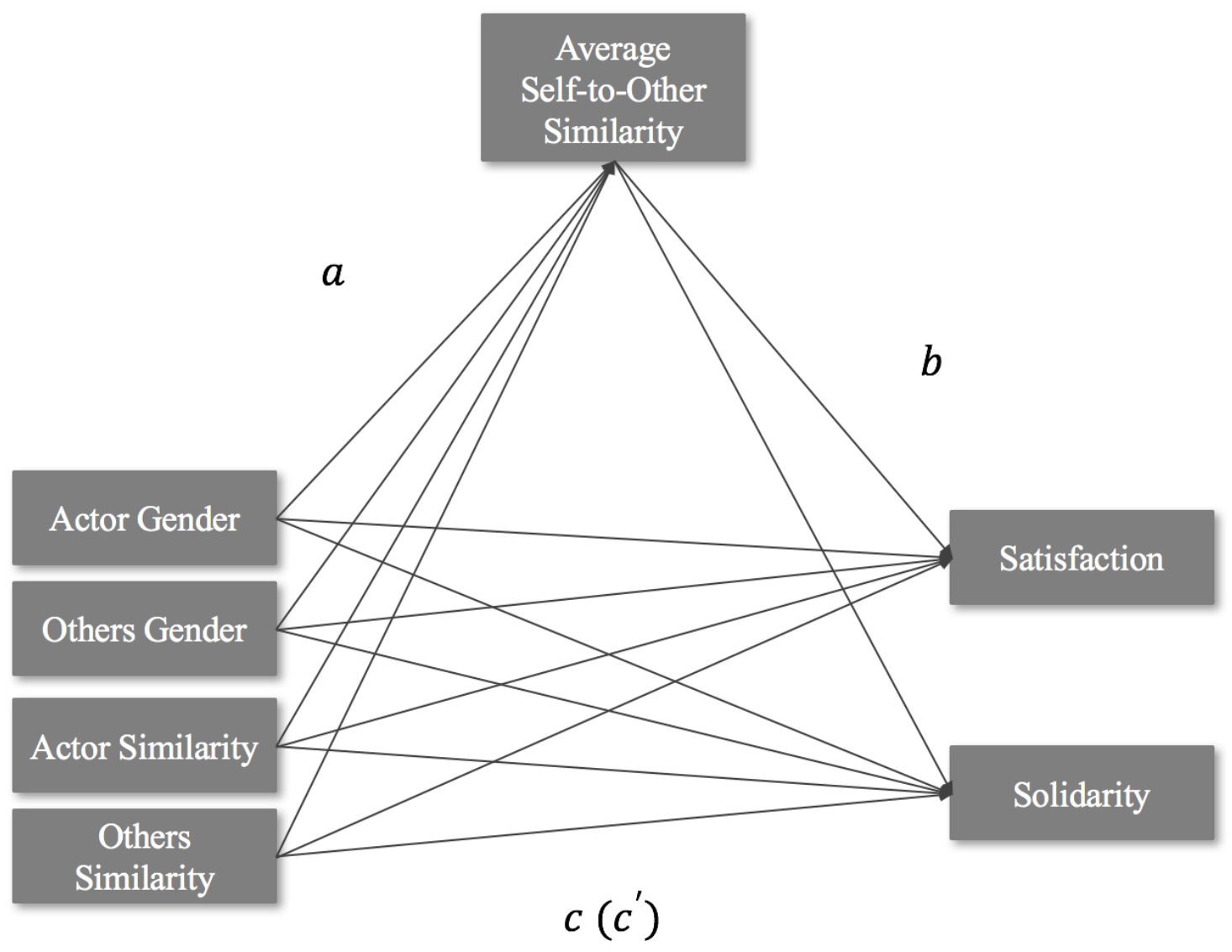

Figure 1. The full mediation diagram of the effects of actual actor similarity in gender on group identification through perceived self-to-other similarity 


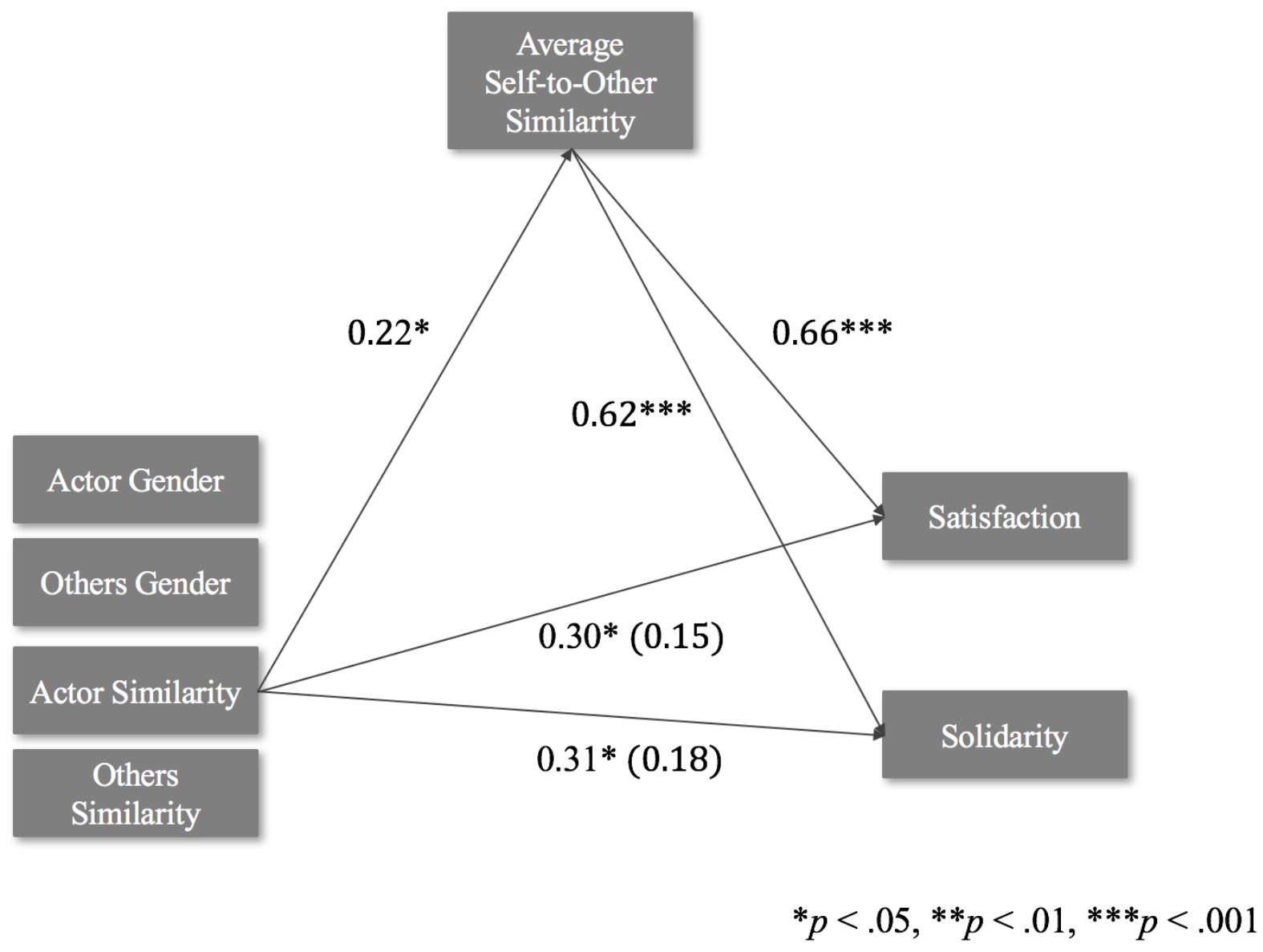

Figure 2. The trimmed mediation diagram of the effects of actual actor similarity in gender on group identification through perceived self-to-other similarity. 